\title{
A Prelude to Insurrection: How a 4chan Refrain Anticipated the Capitol Riot
}

\author{
Marc Tuters
}

\begin{abstract}
This paper looks at how vernacular practices associated with fringe web communities seem to have found their way into reactionary American politics in recent years. Combining concepts from political communication (Bennett and Segerberg 2013) and from assemblage theory (Samson 2020), the paper looks at how key elements of the Capitol insurrection narrative initially emerged on 4chan as meme about a second civil war (called "the Boogaloo"), then spreading to social media and amplified by President Trump. In an effort to make sense of this relationship between the fringe the mainstream, the paper offers both original empirical analysis as well as conceptual innovation.
\end{abstract}

Keywords: Internet memes, post-digital far-right, assemblage theory, connective action, entryism, memetic antagonism, obfuscation, bottom-up agenda setting

In the Trump era a new kind of post-digital far-right activism emerged that spread from fringe regions of the web into corporate social media through the medium of memes. The most notable and widely reported of these was QAnon, the notorious deep state conspiracy theory that made its way into the core of Republican party politics under Trump (Levin 2021) and which seemed to take the form of a real-world game (Thompson 2020). Having started out in late 2017 from a series of anonymous posts the notorious 4chan imageboard (Tuters 2020), over the course of the next few years QAnon developed into a "super conspiracy" (Barkun 2013) incorporating a wide variety of different communities ranging from Tea Party libertarians to New Age anti-vaxxers (Argentino 2020), as it spread from the fringe into the mainstream of public attention (Zeeuw et al. 2020). Part of what drew these different constituencies in and held them together was a sense of collaborative participation in the construction of a narrative-whose subcultural origins made it seem more authentic. Across various social media, the growth of QAnon went largely unchecked over the course of Trump's presidency, and is widely considered to have been a significant contributing factor in galvanizing the motley crew of protestors that stormed the Capitol on January 6th 2021, leading social media platforms to subsequent ban much related content (Conger 2021). As reports of that day later noted, iconography and sloganeering from the fringes of the Internet were a ubiquitous sight on that day (Rosenberg \& Tiefenthäler 2020).

Beyond its shocking violence, a striking aspect of Capitol insurrection was its subcultural pageantry, most notably the infamous "QAnon shaman". A bare chested man with a painted face carrying a spear with an American flag tied below the blade and wearing a fur hat with buffalo horns, this man was photographed standing on the raised platform on the site where the Vice President Mike Pence was supposed to ratify Biden as the new president-while other insurgents wandered through the halls of the Capitol building chanting "hang Mike Pence", some wearing full military body armour. While the events of that day came as a surprise to many Americans, the narrative of a second civil war, had in fact been floated by Trump on Twitter over a year prior and it had been developing online since the spring of 2019 in posts to 4chan by online gun enthusiasts on 4chan whom referred to it coded ironic Internetspeak as the Boogaloo. As described below, 4chan's vernacular conception for a second civil war in turn inspired an 
entire anti-state insurrectionist movement whom referred to themselves as "the Boogaloo Bois" and used vernacular "dissimulation" techniques, adapted from 4chan's subculture (Zeeuw and Tuters 2020), both to create a "playful" movement identity as well as to avoid detection in the context of corporate social media efforts at "deplatforming" (Rogers 2021). As in the cases of QAnon and Pizzagate before it, 4chan provided the nascent movement with a ready-made format for political activism, in the form of an Internet meme. As these far-right memes served Trump's agenda, in political communication terms we may consider them as instances of bottom-up agenda setting. Combining concepts from political communication (Bennett and Segerberg 2013) and from assemblage theory (Samson 2020), this paper analyzes the constitutive role of antagonism in the construction of precarious political movements that connects the fringe with the mainstream — as was so clearly on display on the day of the Capitol insurrection.

\section{How 4chan Innovates Connective Antagonism}

While 4chan is regularly (and often rightly) considered as a kind of cesspool of racism bigotry online, it is also an interesting object of study from a media studies perspective for the ways in which aspects of its technical design affect the kind of connective action that the site affords. In spite its anarchic reputation 4chan can be understood as a highly structured and rule based "subcultural language community", governed by ironic, antagonistic, often hateful forms of play (Peeters et al forthcoming). On 4chan, expressions of political extremism are often so entangled with arcane language games as to confound any clear distinctions between the irony and sincerity — a paradox colloquially referred to in discussion forums as "Poe's Law".

4chan contains 74 discussion forums or "boards" each of which is structured as a list of "threads" opening with an image-hence 4chan as a whole is commonly being referred to as an "imageboard". Boards support only a limited number of threads that are ranked with the newest at the top of the board, so that they gradually disappear from the board unless they receive a new post. Additionally, threads can only accrue a fixed number of posts before they become inactive and then are deleted from the site. These technical features make all conversations on 4 chan ephemeral by design. In addition to its ephemerality, 4chan is designed so that posts are anonymous by default. As a result of this, no matter how familiar a user may be with the community, each time they post anew they essentially appear to others as a complete stranger. In order to negotiate these affordances, posters to 4chan (or "anons") thus need to exhibit fluency with the community's latest vernacular innovations, which has led computer science researchers to describe the site as an "excellent venue" for studying "innovation diffusion" (Bernstein 2011: 56) from LOLcats and Rickrolling to alt-right versions of Pepe the Frog and QAnon. While the incomprehensibility of the 4chan's interface constitutes a significant barrier of entry to outsiders, its innovations make their way into the mainstream due to the paradox of what has been called "meme value" - according to which memes need to be "popular enough to gain traction, but not too popular to become mainstream and be adopted by normies" (Literat and van den Berg 2019: 239).

In an highly cited article on the impact of social media on grassroots activism, the political communications scholars Lance Bennet and Alexandra Segerberg develop the notion of that "connective action", which entails the use of social media to "appropriate, shape, and share" "easy-to-personalize action themes" rather than having to achieve "ideological identification" with a "common group" (2013: 744, 742). Bennet and Segerberg also specifically identify "the meme" as a kind of synecdoche for their theory of political communication: "a symbolic packet that travels easily across large and diverse populations" that provides "action repertoires that might be passed on" (752). Since connective action replaces membership in organizations with a more fluid form of affiliation based on identity, such groups are more open-ended and adaptable. Connective action makes groups more susceptible to "entryism" — a political strategy in which one organization joins another, often by subterfuge, in order to control the latter-a fact overlooked by Bennet and Segerberg. To this point, a common charge amongst old 4chan anons is that the site was essentially over-taken by an organized far-right actors in the aftermath of the law enforcement campaigns against hacker groups related to the Anonymous movement in the mid 2010's - though others contend that the subculture had always been essentially racist (Phillips and Milner 2021: 52). Indeed, before its association with the far-right, scholarship noted the difficulty of pinning down a singular core coherent ideology to 4chan (Uitermark 2017), whose user-base is rarely the same form one moment the next (Phillips et al. 2017). 
Whether or not organized entryism was the main cause of 4chan having become one of the preeminent sites of extremism online, on 4chan the way in which in-group identity formation is tied to out-group antagonism tends to escalate from antagonistic "play" to expressions of downright (often genocidal) hostility. Constantly vying to demonstrate their in-group status, anons have developed arcane techniques by which to distinguish members of the subcultural in-group from "normies" or "NPCs"- the latter an acronym for non-player characters. If we refer to way that 4chan anons use of memes and vernaculars in the process of group identity formation as "memetic antagonism" (Tuters and Hagen 2020), then we might refer to the process by which versions of those memes and slang expressions reach beyond this subcultural language community as one of connective antagonism. From the spread of QAnon to protest as far afield as in Germany and Japan, 4chan vernaculars are becoming a ubiquitous element of what have been called the "post-digital cultures of the far right" (Fielitz and Thurston 2018). Because 4chan's design renders the extraction of users' personalized data essentially impossible, the website is perceived to be an anarchic alternative to the corporatized web of social media platforms whose business model is based on ubiquitous surveillance (Zeeuw and Tuters 2020), with anons cultivating tactics of "opaque resistance" as a means by which to elude discovery by an "all-seeing power" (Certeau 2011: 133, 158). As will be seen in the discussion below, post-digital far right cultures have been adapted some of these vernacular techniques as strategic means of obfuscation (Brunton and Nissenbaum 2015). This argument having been established, let us now move on to consider how one particular 4chan meme, the Boogaloo, would resonate deeply with the theme of the Capitol insurrection-in which an angry mob beat a Capitol police officer to death, while others allegedly sought to murder politicians in the Capitol building-if it did not directly inspire the latter.

\section{The Boogaloo's Birth and Spread}

We can trace the very first time that "boogaloo" was used to refer to the idea of a second American civil war to a series of posts on a 4chan's weapons-themed discussion board, "/k/", in the spring of 2019 (see Figure 1 below).1 The opening post of that thread-which featured an image of the "Spurdo" meme, used to mock normies—asked: "In the event of the boogaloo, how will america be split and which side will win?" (Anonymous 2019a). Over the course of the next months, similar threads would develop the narrative of a violent armed insurrection against the state as "the Boogaloo". Following Trump's aforementioned Tweet, in the fall of 2019, the Boogaloo meme seems to have picked up on Facebook where it held together a loose network of pages devoted to a "Boogaloo Bois" movement, with names like "Big Igloo Bois" and "Big /K/ahuna's Big Luau" (Evans and Wilson 2020)_"igloo" and "luau" being vernacular derivation of boogaloo whose use may be understood in terms of obfuscation techniques for opaque resistance, intended to elude discovery by Facebook's content moderation algorithms.

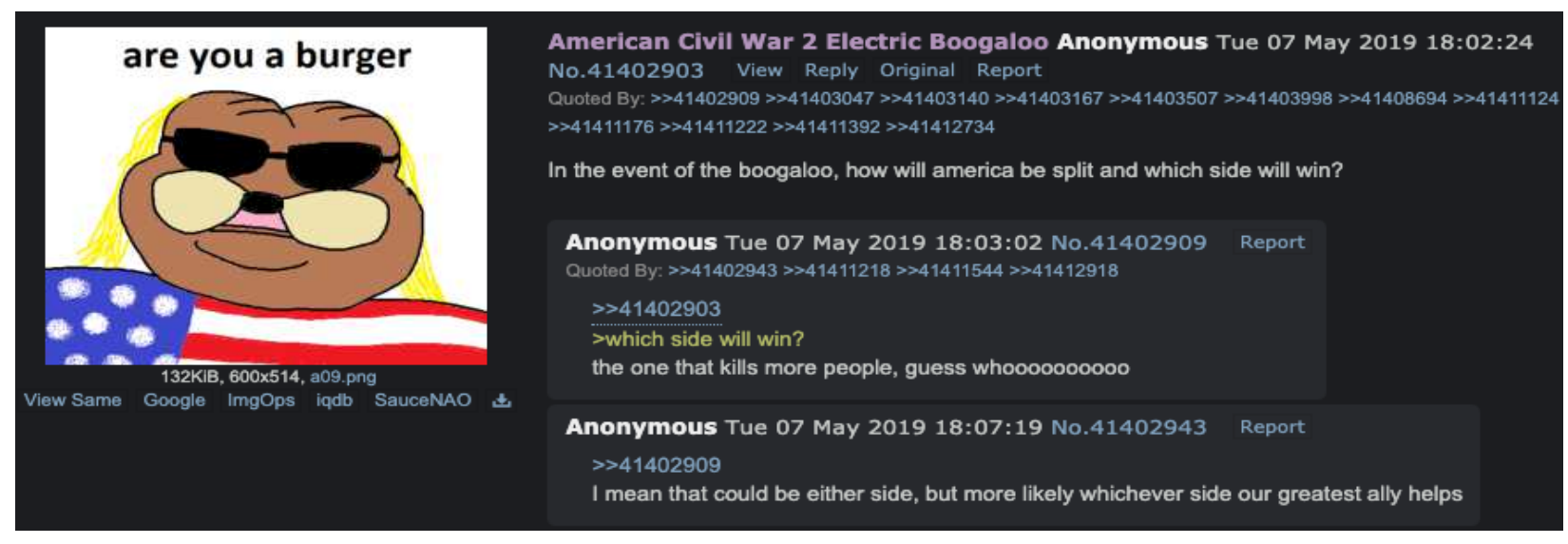

Figure 1. First Boogaloo conversation thread on $4 \mathrm{chan} / \mathrm{k} /$ (Author anonymous).

Already a month after the first 4chan post, anons were disparaging the Boogaloo as a "boring LARP" (Anonymous 2019b)_LARPing referring to a cos-play genre in which gamers "live-action role play" aspects of game mechanics in real-world environments. Yet, though LARPing is typically denigrated on 4chan, on corporate 
social media platforms it has been an important means by which elements of 4chan's subculture have been adapted by the "alt-right" as the basis of post-digital counter-protest tactics (Tuters 2018). On this same model of translating elements of 4chan's subculture for a more mainstream audiences, Boogaloo memes on Facebook explicitly embraced LARPing-for example often using video game language of "quests" and "achievement points" to describe acts of real world violence as though the second American civil war would occur within the diegesis of a game. As self-described Boogaloo Bois increasingly appeared at protests against police violence throughout the summer of 2020 in cosplay outfits that incorporated references to 4chan's meme subculture, including insignias of igloos and luau patterns. Through the use of such playful seeming imagery, Boogaloo Bois seemed to present themselves as merely LARPers - thereby self-consciously obfuscating sincere political commitments under a veil of self-deflating irony and arcane references to in-group vernaculars. This paradoxical position of participating in extremist political activism while seeing oneself also as player in a game was also a common characteristic amongst the Capitol rioters, many of whom would later consider themselves to have been played by Trump.

Of the many different fringe far-right groups that covered on the Capitol on January 6th, perhaps none was more single-mindedly focussed on violent insurrection than the Boogaloo Bois. In both their preoccupation with guns as well as their anti-state politics, the Boogaloo Bois appeared superficially akin to the organized militia movements whose membership had dramatically grown over the last decades in the United States (Belew 2018). In contrast, however, to movements that feature membership in formal organizations the Boogaloo Bois seemed to lack a clear ideological foundation-which indeed Bennet and Segerberg claim to be one of the characteristics of Internetenabled connective action. (In their extreme hostility to federal law enforcement, on occasion Boogaloo Bois for example appeared to align themselves with Black Lives Matter protesters — to whom many Trump supporters were fundamentally opposed.) Counter-terrorism experts warm however that the Boogaloo Bois strategically exploited the seeming lack of coherence of their connective action movement, in order to obfuscate what was in essence an extreme-right ideology (Newhouse and Gunesch 2020).

\section{When you and the boys go full boogaloo and baptize all the politicians at the capital building and now it's completely surrounded by the National Gaurd and you can hear Seal Team 6 Roping in on the roof and the boys are asking you what to do now.}

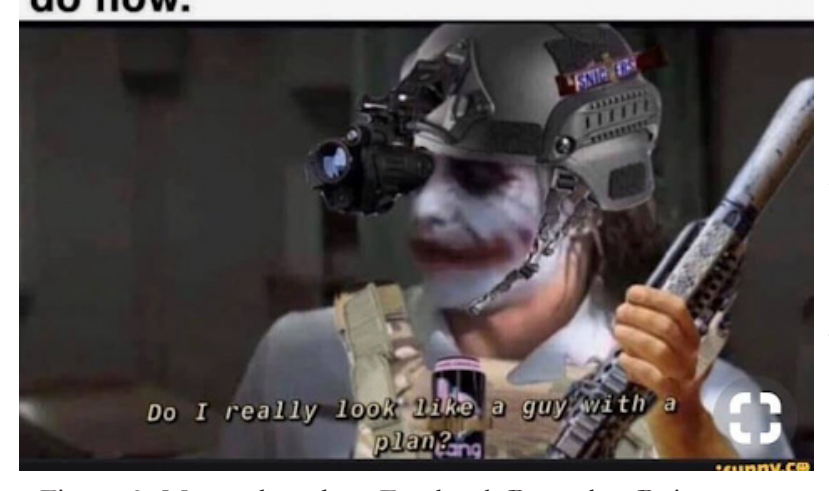

Figure 2. Meme shared on Facebook Boogaloo Bois groups. (2020, author anonymous).
While several Boogaloo Bois were arrested for their role in the Capitol insurrection (Sanchez and Mallin 2021), the movement appears not to have been central in organizing the riot. In retrospect, we may consider the idea of the Boogaloo-which is to say a second civil war live-action role-play — as having created a memetic template for the Capitol rioters. In particular, one Boogaloo meme widely shared on Facebook and other social media in the summer of 2020 seems to support this claim (see Figure 2 below). The meme features an image of a comic book villain photoshopped to appear as though in Boogaloo garb with a caption reading: "when you and your boys go full boogaloo and baptize all the politicians at the capital [sic] building and now it's completely surrounded by National Gaurd [sic] [...] and the boys are asking you what to do." Another caption at the bottom of the image provides a response: "Do I really look like a guy with a plan?" Indeed, around the time that this image was being circulated, several months prior to the Capitol insurrection, a group of self-identified Boogaloo Bois would be charged with conspiracy to kidnap the governor of the state of Michigan (Department of Justice 2021). The way in which such Boogaloo memes appear to have prefigured the Capitol insurrection calls for some conceptual innovation into how and why (so-called) memes have so frequently moved from 4chan to Facebook, to which we move in the next and last section. 


\section{On Social Media’s Dark Refrains}

The American far-right had long been characterized by their innovative use of new media and of discussion forums (Niewert 2017). Seen from this historical perspective, Boogaloo memes are merely the latest in a long series of bizarre extreme-right subcultures that date back to the late-1970's, and which have experienced a renaissance on 4chan (Tuters and OILab 2019). What appears relatively novel, however, is the degree to which a far-right ideology is entangled with the distinctly subcultural style of contemporary imageboards, as well as the dynamics by which farright action formats appear again and again to move from 4chan into the mainstream of social media. While 4chan anons constantly produce antagonistic memes and narratives, relatively rarely do they reach much beyond into the mainstream. What set QAnon, Pizzagate and the Boogaloo apart was their alignment with Trump's agenda as well as a social media ecosystem that seemed to valourize such connective antagonisms.

Trump style of political communication has often been a catalyst in the process of mainstreaming the icons and narratives of the fringe Internet. Key to their success is the capacity of these memes to create connections between different antagonistic groups with differing degrees of commitment connections. In particular, 4chan memes have repeatedly proven extremely effective at radicalizing the base through the uptake of vernaculars favoured by the far-right - such as with the spread of the anti-semitic triple parentheses meme from 4chan to Facebook (Tuters and Hagen 2020). Although own Trump's words on the alt-right, QAnon and the Proud Boys suggest an awareness of 4chan-adjacent fringe movements' beliefs, it is plausible that Trump recognized them as primarily for their outrageous sensationalism. In this respect, Trump's political communication style shared something with Facebook and other similar corporate social media which, according to the science studies scholar Noortje Marres, are designed to valourize content that is "sensational, often outrageous and extremist" and exhibit a general "disrespect for knowledge" that Marres claims "has something to do with the dominant conception and design of social media platforms as a behavioral domain, where users are often framed as influence-able subjects" (Marres 2018: 430, 435). As the political figure with "most engaged with" page of Facebook, Trump well understood how platform's content metrics valourized antagonism, and was always in search of new ways to express that theme (cf Kang and Frenkel 2021).

It has been suggested that the reason that 4chan memes do so well on social media is that they have grown superresilient by adapting to its exceptionally harsh (and essentially meaningless) communication environment (Venturini in review). While phenomena originating on 4chan such as QAnon and Boogaloo are often conceptualized through the evolutionary theory of memetics, the media scholar Tony Sampson has argued that memetics is a poor concept for analyzing the essential role of media in their propagation because of the fact that "in memetics, the medium in which an idea is transmitted is typically dismissed as an inert channel" (2012, p.72). Departing from that critique, in his most recent monograph, "A Sleepwalker's Guide to Social Media" (2020), Sampson has developed an alternative to that of the meme in order to better understand the relationship between right-wing demagogues and the Internet. Sampson writes of a "staccato-like repetition of a racist populist politics, spreading throughout the world" that is facilitated by demagogues' use of social media, which he refers to as a dark refrain drawing on assemblage theory (2020: 4). In Deleuze and Guattari's assemblage theory the concept of "the refrain" relates to their notion of "milieu", which they define as "a block of space-time" that is coded by "periodic repetition", in which "one milieu serves as the basis for another" such that the milieus "are essentially communicating" (1993: 313). This conceptual lens offers a way to think about the Boogaloo meme as kind of pattern that repeats itself as part of a larger arrangement, as in a fugue. The "staccato rhythms" of Trump's political communication style can thus be understood as resonating with and reiterating aspects of the ephemeral milieu of from which they emerged. From this Deleuzoguattari perspective, communication is less a question of conveying information than it is of patterning of unconscious obedience to the imagined desires of the vernacular language community (Peeters et al, forthcoming).

Thus conceived, we can understand Boogaloo memes on Facebook as having encoded 4chan's memetic antagonism as the basis for a form of cross-platform connective action that was the key leitmotif in the storming of the Capitol. This framework helps us to appreciate how populist demagogues like Trump's use social media to orchestrate antagonisms between different reactionary milieus via connective "memes" without necessarily having to 
fully grasp their manifest significance. Through the Deleuzoguattari refrain, we can understand how Trump has used social media to orchestrate the repetition of repetitive motifs in an arrangement whose players include elements from the fringes of web subcultures in positions of importance. To put this in more conventional political communication terms, we can say that Trump engages in a kind of bottom-up agenda setting, amplifying elements so as to orchestrate them. Rendered possible by the way that platforms' valourizes "user engagement", this demagogic style of political communication echoes the Deleuzoguattarian contention that fascism is only ever appropriated by state power "but it finds its energy right at the heart of everyone's desire" (Guattari 1992: 245). So long as the bottom line of platforms' extactivist business model is to capture and incentivize users' every need (Srnicek 2017), they will remain susceptible to the orchestration of dark refrains.

While the recent rise on extremism on corporate social media has been explained as matter of content producers responding to extant user demand (cf Munger and Phillips 2020) such a market explanation overlook platforms' own culpability in creating the conditions that structure the emergence of extreme speech markets (cf Keulenaar et al forthcoming). Following Deleuze and Guattari, we need to appreciate how media are never simply inert channels, but instead function as substrates with which specific kinds of desire can develop and proliferate-with certain circumstances tending towards the toxic. The spectacular success of QAnon, the Boogaloo and other fringe refrains has made abundantly clear just how easy it is to produce toxic desires in the current platform assemblages. Given their awesome reach and potentially destructive power, Americans could take a much more active role in considering what kind of desires they truly value and how to regulate platforms accordingly. 


\section{Endnotes}

1. For this analysis third party archives of $4 \mathrm{chan} / \mathrm{k} /$ were used as well as Facebook's Crowdtangle software and Google's reverse image search feature. Since the term "boogaloo" had long been used as a joke in online forum discussions, the analysis required data cleaning and query design.

\section{References}

Anonymous. May 07, 2019a. American civil war 2 electric boogaloo. 4chan/k/ thread. https://desuarchive.org/k/thread/41402903/\#q41402903. Accessed January 20, 2021.

Anonymous. June $152019 \mathrm{~b}$. The boogaloo LARP is boring, can we move on yet. $4 \mathrm{chan} / \mathrm{k} /$ post. https:// desuarchive.org/k/thread/41769291/\#q41770046. Accessed January 20, 2021.

Argentino, Marc-André. May 18 2020. “The Church of QAnon: Will Conspiracy Theories Form the Basis of a New Religious Movement?." The Conversation. https://theconversation.com/the-church-of-qanonwill-conspiracy-theories-form-the-basis-of-a-new-religious-movement-137859. Accessed January 20, 2021.

Barkun, Michael. 2013. A Culture of Conspiracy: Apocalyptic Visions in Contemporary America. Berkeley: University of California Press.

Belew, Kathleen. (2018). Bring the war home: The white power movement and paramilitary America. Cambridge: Harvard University Press.

Beran, Dale. (2019). It came from something awful: How a toxic troll army accidentally memed Donald Trump into office. New York: All Points Books.

Bernstein, Michael S, Andres Monroy-Hernandez, Drew Harry, Paul Andre, Katrina Panovich, and Greg Vargas. 2011. "4chan and /b/: An analysis of anonymity and ephemerality in a large online community”. Barcelona International AAAI Conference on Weblogs and Social Media, 5 (2011, Spain).
Bennett, W. Lance and Segerberg, Alexandra. 2012. "The logic of connective action". Information, Communication \& Society, 15(5): 739-768.

Brunton, Finn and Helen Nissenbaum. 2015. Obfuscation: A User's Guide for Privacy and Protest. Cambridge: MIT Press.

Certeau, Michel. 2011. The practice of everyday life. Berkeley: University of California Press.

Conger, Kate. Jan. 11, 2021. Twitter, in Widening Crackdown, Removes Over 70,000 QAnon Accounts. New York Times. https://www. nytimes.com/2021/01/11/technology/twitter-removes-70000-qanon-accounts.html. Accessed January 20, 2021.

Deleuze, Giles and Felix Guattari. 1993. A thousand plateaus: Capitalism and schizophrenia. Minneapolis: University of Minnesota Press.

Department of Justice. April 28, 2021. "Federal Grand Jury Returns a Superseding Indictment Adding New Charges in the Conspiracy to Kidnap Michigan Governor Gretchen Whitmer”

https://www.justice.gov/opa/pr/federal-grand-jury-returns-superseding-indictment-adding-new-charges-conspiracy-kidnap. Accessed May 20, 2021.

Evans, Robert and Jason Wilson. May 27, 2020. The Boogaloo Movement Is Not What You Think. Bellingcat. https://www.bellingcat.com/ news/2020/05/27/the-boogaloo-movement-is-notwhat-you-think/. Accessed May 20, 2021. 
Fielitz, Maik, and Nick Thurston. 2018. Post-digital cultures of the far right online actions and offline consequences. Berlin: Transcript Verlag.

Guattari, Felix. 1992. Chaosmosis: An Ethico-Aesthetic Paradigm. Chaosmosis: An Ethico-Aesthetic Paradigm. Bloomington: Indiana University Press.

Kang, Cecilia and Sheera Frenkel. 20201. An Ugly Truth: Inside Facebook's Battle for Domination. New York: Harper Collins

Keulenaar, Emillie, Marc Tuters, Cassian OsborneCarey, Daniel Jurg and Ivand Kisje. forthcoming. "A Free Market in Extreme Speech: Scientific Racism and Bloodsports on YouTube". Digital Scholarship in the Humanities.

Levin, Bess. February 4 2021. Marjorie Taylor Greene: I Only Believe Some of What QAnon Says About Dems Being Satanic Pedophile Cannibals, Okay? Vanity Fair. https://www.vanityfair.com/news/2021/02/marjorie-taylor-greene-fake-mea-culpa. Accessed March 1,2020 .

Literat, Ioana and Sarah Van Den Berg. 2019. "Buy memes low, sell memes high: vernacular criticism and collective negotiations of value on Reddit's Meme Economy". Information, Communication \& Society, 22(2): 232-249.

Marres, Noortje. 2018. “Why We Can't Have Our Facts Back." in Engaging Science, Technology, and Society 4: 423-443.

Munger, Kevin, Phillips, Joseph. 2020. Right-Wing YouTube: A Supply and Demand Perspective. The International Journal of Press/Politics. 21(2)

Neiwert, David. 2017. Alt-America: The rise of the radical right in the age of Trump. London: Verso.

Newhouse, Alex and Nate Gunesch. May 30, 2020. The Boogaloo Movement Wants To Be Seen as Anti-Racist, But It Has a White Supremacist Fringe. Middlebury. edu. https://www.middlebury.edu/institute/ academics/centers-initiatives/ctec/ctec-publications/ boogaloo-movement-wants-be-seen-anti-racist-it. Accessed January 20, 2021.
Newton, Casey. June 30 2020. "Facebook is removing a network of accounts linked to the violent 'Boogaloo' movement." The Verge. https://www.theverge. com/2020/6/30/21308572/facebook-boogaloogroup-network-removal-ban-civil-war-violence. Accessed January 20, 2021

Noys, Benjamin. 2010. The Persistence of the Negative. Edinburgh: Edinburgh University Press.

Owen, Tess. May 29, 2020. Far-Right Extremists Are Hoping to Turn the George Floyd Protests Into a New Civil War. https://www.vice.com/en/article/pkyb9b/ far-right-extremists-are-hoping-to-turn-the-georgefloyd-protests-into-a-new-civil-war. Accessed January 20, 2021.

Phillips, Whitney, and Ryan Milner. 2021. You Are Here: A Field Guide for Navigating Polarized Speech, Conspiracy Theories, and Our Polluted Media Landscape. Cambridge: MIT Press.

Phillips, Whitney, Jessica Beyer, and Gabriella Coleman. March 22 2017. "Trolling Scholars Debunk the Idea That the Alt-Right's Shitposters Have Magic Powers." Motherboard. https://motherboard.vice.com/en_us/ article/z4k549/trolling-scholars-debunk-the-ideathat-the-alt-rights-trolls-have-magic-powers. Accessed January 20, 2021.

Peeters, Stijn, Marc Tuters, Tom Willaerts and Daniel de Zeeuw. forthcoming. "On the Vernacular Language Games of an Antagonistic Online Subculture" in Frontiers in Big Data, section Big Data Networks.

Rogers, Richard. 2020. 'Deplatforming: Following extreme Internet celebrities to Telegram and alternative social media', European Journal of Communication, 35(3), pp. 213-229.

Rosenberg, Matthew and Ainara Tiefenthäler. January 13 2020. "Decoding the Far-Right Symbols at the Capitol Riot.” New York Times. https://www.nytimes. com/2021/01/13/video/extremist-signs-symbols-capitol-riot.html. Accessed January 20, 2021.

Sanchez, Rosa and Alexander Mallin. February 12 2021. "FBI Arrests 2 'Boogaloo Bois'-Associated Militia Members, 1 Who Incited Riot on Jan. 6." ABC News. https://abcnews.go.com/US/ 
fbi-arrests-boogaloo-bois-militia-members-incited-riot/story?id=75845610. Accessed July 20, 2021.

Sampson, Tony D. 2012. Virality: Contagion Theory in the Age of Networks. Minneapolis: University of Minnesota Press.

Sampson, Tony. 2020. A Sleepwalker's Guide to Social Media. London: Polity.

Srnicek, Nick. 2017. Platform Capitalism. Cambridge, UK: Polity.

Tanner, Charles and Burghart, Devin. 2020. From alt-right to groyper: White nationalists rebrand for 2020 and beyond. Institute for Research \& Education on Human Rights. https://www.irehr.org/reports/altright-to-groyper/. Accessed January 20, 2021.

Thompson, Clive. September 22, 2020. "QAnon Is Like a Game-a Most Dangerous Game.” Wired. https:// www.wired.com/story/qanon-most-dangerous-multiplatform-game/. Accessed January 20, 2021.

Tuters, Marc. 2018. "LARPing \& liberal tears: Irony, belief and idiocy in the deep vernacular web". Fielitz, Maik, and Nick Thurston (Eds), Post-digital cultures of the far right online actions and offline consequences. Transcript Verlag: 37-48.

Tuters, Marc. 2020. The birth of QAnon: On how 4chan invents a conspiracy theory. Open Intelligence Lab. https://oilab.eu/the-birth-of-qanon-on-how-4chaninvents-a-conspiracy-theory/. Accessed January 20, 2021.

Tuters, Marc and Hagen, Sal. 2020. “(((They))) rule: Memetic antagonism and nebulous othering on 4chan." New Media \& Society, 22(12): 2218-2237.

Tuters, Marc and OILab. 2020. "Esoteric fascism online 4chan and the Kali Yuga". In Louis Dean. ValenciaGarcia (Ed.). Far-Right Revisionism and the End of History. New York: Taylor Francis: 287-303.

Uitermark, Justus. 2017. "Complex Contention Analyzing Power Dynamics Within Anonymous." Social Movement Studies 16 (4): 403-17.

Venturini, Tommaso. (manuscript in review) "A Sociology of Online Monsters: Online Conspiracy
Theories and the Secondary Orality of Digital Platforms". Submitted to Theory Culture \& Society.

Zeeuw, Daniel and Marc Tuters. 2020. "Teh Internet is Serious Business: On the Deep Vernacular Web and Its Discontents". Cultural Politics, 16(2): 214-232.

Zeeuw, Daniel, Sal Hagen, Stijn Peeters and Emilija Jokubauskaite. 2020. "Tracing Normiefication: a Cross-Platform Analysis of the QAnon Conspiracy Theory." First Monday 25 (11). https://firstmonday. org/ojs/index.php/fm/article/view/10643/9998. 